\title{
Evaluasi Program Pelatihan Manajemen Unit Ruang Rawat (Kirkpatrick Level I Dan II) Di RSUD Praya-Nusa Tenggara Barat, 2020
}

\author{
Lalu M.Harmain Siswanto ${ }^{1,2) *}$ \\ Email: lalusiswantoui@gmail.com \\ 1) Universitas Qamarul Huda Bagu \\ ${ }^{2)}$ Bapelkes Provinsi NTB
}

\begin{abstract}
ABSTRAK
Pelatihan Manajemen unit ruang rawat bertujuan Agar Kepala Ruang Rawat semakin terampil dan mampu melaksanakan tugasnya secara efektif dan efisien, maka diperlukan pengembangan diri melalui pelatihan yang sesuai. Kegiatan evaluasi pelatihan perlu dilakukan untuk mengetahui keberhasilan dari sebuah pelatihan manajemen unit ruang rawat yang sudah diselenggarakan. Mengingat belum pernah dilakukan evaluasi terhadap pelatihan tersebut. Untuk mengetahui hasil evaluasi fasilitator, penyelenggaraan dan evaluasi pengetahuan peserta Penelitian ini merupakan jenis penelitian kuantitatif. Desain penelitian deskriptif observasional. Pendekatan yang digunakan prospektif. Populasi untuk penelitian ini adalah Manajer perawat. Jumlah peserta pelatihan manajemen unit ruang rawat pada penelitian ini adalah 30 orang. Evaluasi yang dilakukan menggunakan Model KirkPatrick Level 1 dan 2 yaitu Reaksi (evaluasi peserta, fasilitator dan Penyelnggaraan) dan Pembelajaran (Pengetahuan Peserta). Instrumen untuk Level 1 menggunakan Lembar evaluasi Fasilitator, Penyelenggaraan, Level 2 menggunakan Lembar evaluasi soal Pre Post Test. Hasil penelitian ini secara umum di dapatkan bahwa Evaluasi peserta pelatihan terhadap Narasumber yaitu dalam kategori sangat baik dan evaluasi Penyelenggaraan Pelatihan menggambarkan baik. Pengetahuan peserta pelatihan sebelum pelatihan sebesar 76,7\% kategori cukup dan setelah pelatihan $90 \%$ dalam kategori baik. Pelatihan berjalan dengan baik dibuktikan dengan hasil pengetahun peserta pelatihan meningkat. Pelatihan perlu di adakan di rumah sakit lain dengan memperhatikan kaidah-kaidah pelatihan. Perlu menjadi masukan untuk peneliti selanjutnya menggunakan metode kualitatif atau mix metode untuk melihat lebih dalam terkait penyelenggaraan pelatihan.
\end{abstract}

Kata kunci: Pelatihan, Manajemen unit Ruang Rawat, evaluasi.

\begin{abstract}
The management of ward unit training aims to make the Head of the Ward more skilled and able to carry out his duties effectively and efficiently, it is necessary to develop himself through appropriate training. Training evaluation activities need to be carried out to determine the success of a training room management unit that has been held. Given that there has never been an evaluation of this training. To find out the results of the evaluation of the facilitators, the implementation and evaluation of the participants' knowledge. This research is a type of quantitative research. Observational descriptive research design. The approach used prospectively. The population for this study were nurse managers. The number of participants in the training of inpatient room management in this study was 30 people. The evaluation was carried out using the KirkPatrick Level 1 and 2 Model namely Reaction (participant evaluation, facilitator and implementation) and Learning (Participant Knowledge). Instruments for Level 1 use the Evaluation Sheet for Facilitators, Implementation, Level 2 using the evaluation sheet for the Pre Post Test questions. The results of this study generally show that the training participants' evaluation of resource persons is in the very good category and the evaluation of the training is good. The knowledge of the training participants before training was $76.7 \%$ in sufficient category and after training $90 \%$ in good category. The training went well as evidenced by the increase in the training participants' knowledge. Training needs to be held in other hospitals by paying attention to training principles. It needs to be input for further researchers to use qualitative methods or a mix of methods to have a deeper look at the implementation of training.
\end{abstract}

Keywords: Training, Management of ward units, evaluation. 


\section{A. LATAR BELAKANG}

Manajemen keperawatan merupakan proses perencanaan, pengorganisasian, pengaturan staf, pengarahan, dan pengendalian yang satu sama lain saling terkait. Peran manajer keperawatan tidak terlepas dari proses manajemen yang dilakukan, termasuk menerapkan perhatian kepada sumber daya material maupun sumber daya manusia keperawatan. Peran manajer yang diterapkan secara nyata mampu membawa transformasi bagi staf keperawatan lainnya untuk menerapkan standar mutu keperawatan [1]. Standar ditetapkan untuk mengukur performa asuhan dan pelayanan keperawatan yang bersifat obyektif, dapat diukur, dan dapat dicapai [4].

Peran utama seorang Kepala Ruang Rawat adalah mengelola seluruh sumber daya di unit perawatan untuk menghasilkan pelayanan yang bermutu. Kepala Ruang Rawat merupakan jabatan yang cukup penting dan strategis, karena secara manajerial kemampuan kepala ruang rawat menentukan keberhasilan pelayanan keperawatan. Dimana hal utama yang diberikan pihak rumah sakit kepada (pasien) adalah pelayanan. Dan pelayanan pertama yang didapatkan oleh pasien adalah unit ruang rawat, sehingga dapat dikatakan kesan pertama bagi pasien adalah unit ruang rawat. Pelatihan Manajemen unit ruang rawat bertujuan Agar Kepala Ruang Rawat semakin terampil dan mampu melaksanakan tugasnya secara efektif dan efisien, maka diperlukan pengembangan diri melalui pelatihan yang sesuai.

Hasil penelitian memperlihatkan bahwa terkait fungsi manajemen kepala ruangan teridentifikasi fungsi perencanaan, pengarahan dan pengendalian terkait penerapan indikator mutu keperawatan masih perlu ditingkatkan ,penerapan fungsi pengendalian mutu keperawatan oleh kepala ruangan belum optimal dalam hal tindak lanjut dari hasil capaian mutu. Selain itu pelibatan kepala ruangan dalam penetapan indikator mutu keperawatan. Kurangnya pelibatan kepala ruangan tersebut berdampak pada belum difahaminya definisi dari masing-masing indikator mutu yang dipantau [6].

Kegiatan evaluasi dilakukan untuk mengetahui keberhasilan dari sebuah pelatihan manajemen unit ruang rawat yang sudah diselenggarakan. Dalam hal ini adalah evaluasi pelatihan manajemen unit ruang rawat.Evaluasi pelatihan dilakukan (1). Mengetahui hasil pelaksanaan pelatihan dan pengaruhnya terhadap kinerja serta masalah-masalahnya; Mengetahui opini pemimpin dan bawahan peserta mengenai hasil pelatihan; (3). Mengetahui hubungan hasil pelatihan serta dampaknya bagi organisasi di tempat peserta bekerja.[5]

Mengingat pentingnya kegiatan evaluasi terhadap sebuah program pelatihan tersebut, berdasarkan fenomena di atas , maka peneliti tertarik untuk menelaah secara empiris tentang Evaluasi program Pelatihan Manajemen Unit Ruang Rawat yang sudah dilaksanakan dengan melakukan evaluasi sejauh mana terhadap fungsi manajemen yang sudah dilaksanakan oleh perawat manajer setelah mengikuti pelatihan. Evaluasi yang dilakukan terkait level 1 dan 2 model evaluasi Kirkpatrick.

\section{B. METODE PENELITIAN}

Penelitian ini merupakan jenis penelitian kuantitatif. Desain penelitian deskriptif observasional. Pendekatan yang digunakan prospektif. Populasi untuk penelitian ini adalah Manajer perawat. Jumlah peserta pelatihan manajemen unit ruang rawat pada penelitian ini adalah 30 orang. Evaluasi yang dilakukan menggunakan Model KirkPatrick Level 1 dan 2 yaitu Reaksi (evaluasi peserta, fasilitator dan Penyelnggaraan) dan Pembelajaran (Pengetahuan Peserta). Instrumen untuk Level 1 menggunakan Lembar evaluasi Fasilitator, Penyelenggaraan, Level 2 menggunakan Lembar evaluasi soal Pre Post Test.

\section{HASIL DAN PEMBAHASAN}

Hasil penelitian ini didapatkan evaluasi 
pelatihan manajemen unit ruang rawat menggunakan model Kirkpatrick level 1 dan 2 yaitu didapatkan evaluasi pelatihan terkait narasumber/fasilitator, penyelenggaraan pelatihan dan evaluasi terhadap pengetahuan peserta.

1. Evaluasi Level I, Gambaran evaluasi peserta pelatihan terhadap Narasumber dan Penyelenggaraan Pelatihan manajemen unit ruang rawat

Tabel 1

Distribusi Frekuensi Evaluasi terhadap narasumber Pelatihan Manajemen Unit Ruang Rawat $(n=30)$

\begin{tabular}{|l|l|l|}
\hline Kategori & Jumlah & Persentase \% \\
\hline Sangat Baik & 21 & 70 \\
\hline Baik & 8 & 26,7 \\
\hline Cukup & 1 & 3,3 \\
\hline Kurang & 0 & 0 \\
\hline Jumlah & $\mathbf{3 0}$ & $\mathbf{1 0 0}$ \\
\hline
\end{tabular}

Tabel di atas menggambarkan tentang evaluasi Narasumber pelatihan secara umum memunjukkan bahwa 21 orang (70\%) menyatakan Penyampaian Materi oleh Narasumber pelatihan dengan sangat baik.

\section{Diagram 1}

Gambaran Evaluasi Narasumber Pelatihan Manajemen unit Ruang Rawat $(n=30)$

Pelatihan Manajemen unit Ruang Rawat 2018 RSUD Praya, 12 - 14 oktober 2018

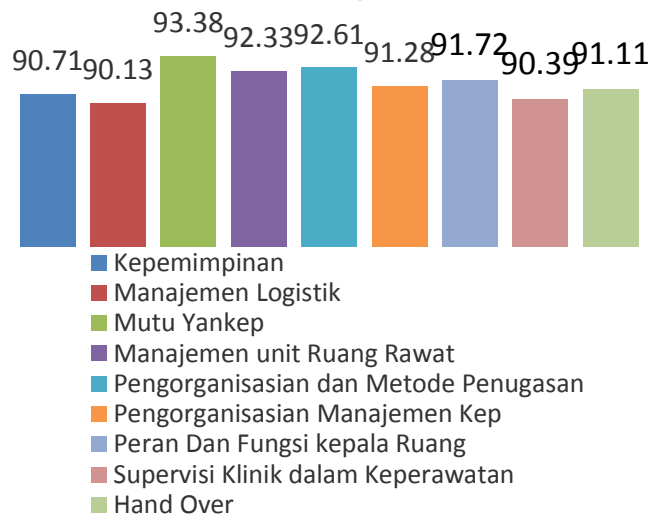

Diagram di atas menunjukkan bahwa evaluasi terhadap fasilitator oleh peserta dan dari hasil evaluasi menunjukkan bahwa semua fasilitator mempunyai evaluasi sangat baik, Materi Mutu pelayanan Keperawatan menunjukkan 93,38\% sangat baik dari evaluasi peserta.

Tabel 2

Distribusi Frekuensi Evaluasi Penyelenggaraan

Pelatihan Manajemen Unit Ruang Rawat $(n=30)$

\begin{tabular}{|l|l|l|}
\hline Kategori & Jumlah & Persentase \% \\
\hline Sangat Baik & 7 & 23,3 \\
\hline Baik & 15 & 50 \\
\hline Cukup & 7 & 23,3 \\
\hline Kurang & 1 & 3,3 \\
\hline Jumlah & $\mathbf{3 0}$ & $\mathbf{1 0 0}$ \\
\hline
\end{tabular}

Dari table di atas menjelaskan gambaran evaluasi penyelenggaraan menunjukkan bahwa Sebagian peserta 15 orang (50\%) menyatakan penyelenggaraan pelatihan dalam kategori Baik.

2. Evaluasi Level II, Gambaran pengetahuan peserta pelatihan tentang manajemen unit ruang rawat sebelum, sesudah pelatihan

Tabel 3

Distribusi Frekuensi Pengetahuan Peserta sebelum Pelatihan Manajemen Unit Ruang Rawat $(n=30)$

\begin{tabular}{|c|c|c|}
\hline Kategori & Jumlah & Persentase \% \\
\hline Baik & 4 & 13,3 \\
\hline Cukup & 23 & 76,7 \\
\hline Kurang & 3 & 10 \\
\hline Jumlah & 30 & 100 \\
\hline
\end{tabular}

Table di atas menunjukkan bahwa pengetahuan peserta pelatihan sebelum pelatihan dimulai hampir Sebagian besar 23 orang $(76,7 \%)$ mempunyai kategori pengetahuan cukup tentang manajemen unit ruang rawat.

Tabel 4

Distribusi Frekuensi Pengetahuan Peserta sesudah Pelatihan Manajemen Unit Ruang Rawat $(n=30)$

\begin{tabular}{|l|l|l|}
\hline Kategori & Jumlah & Persentase \% \\
\hline Baik & 30 & 100 \\
\hline Cukup & 0 & 0 \\
\hline Kurang & 0 & 0 \\
\hline Jumlah & $\mathbf{3 0}$ & $\mathbf{1 0 0}$ \\
\hline
\end{tabular}

Table di atas menjelaskan bahwa 
pengetahuan peserta setelah mengikuti pelatihan menunjukkan 30 orang (100\%) mempunyai kategori baik. Hal ini menunjukkan terjadi peningkatan pengetahuan peserta latih dari sebelum pelatihan dan setelah pelatihan.

Pembahasan untuk evaluasi Level I, Evaluasi peserta pelatihan terhadap Narasumber dan Penyelenggaraan Pelatihan manajemen unit ruang rawat.

Evaluasi peserta pelatihan terhadap narasumber menunjukkan bahwa $70 \%$ peserta menyatakan narasumber sangat baik dalam memberikan materi, $26,7 \%$ peserta menyatakan baik dan 3,3\% peserta menyatakan cukup baik.

Hasil evaluasi terhadap narasumber pelatihan menunjukkan bahwa lebih dari separuh peserta menyatakan narasumber pelatihan sangat baik, hal itu menggambarkan bahwa narasumber pelatihan sudah memberikan yang terbaik kepada peserta sesuai dengan tujuan yang diharapkan. Dari hasil evaluasi juga didapatkan bahwa dari dua belas kriteria evaluasi menunjukkan bahwa kriteria unsur evaluasi Penguasaan materi mempunyai kriteria penilaian paling tinggi yaitu rata-rata $91,33 \%$ artinya sangat baik.

Evaluasi terhadap narasumber merupakan bagian dari evaluasi reaksi [3]. Narasumber yang baik dan mumpuni akan memberikan reflikasi pengetahuan dan keterampilan sebaik-baiknya kepada peserta latih, karena perannya bukan hanya pada saat pelatihan tetapi setelah pelatihan berakhir tetap mempunyai kesempatan untuk berbagi dan membimbing. Peran dari fasilitator sangat besar di antaranya sebagai model, energiser, envisioner, feedback giver, eye opener, door opener, problem solver, conselor dan challenger Sehingga dengan peran fasilitator, narasumber yang begitu besar menjadikannya faktor yang sangat penting dalam pelatihan [4].

Sedangkan evaluasi peserta terhadap penyelenggaraan pelatihan oleh rumah sakit hasil menunjukkan bahwa $23,3 \%$ peserta menyatakan penyelenggaraan sangat baik, $50 \%$ peserta menyatakan penyelenggaraan baik, 23,3\% menyatakan cukup baik dan 3,3\% menyatakan kurang baik. Penyelenggaraan pelatihan yang baik adalah pelatihan yang diselenggarakan dengan manajemen yang baik. Memenuhi kaidah perencanaan kegiatan sebagai bagian dari persiapan, pelaksanaan sesuai perencanaan dan melakukan evalausi. Dari 11 kriteria evaluasi penyelenggaraan didapatkan juga bahwa $43 \%$ peserta menyatakan kenyamanan ruang belajar masih kategori cukup dan adanya 3,3\% menyatakan penyediaan dan kebersihan kamar kecil masih kurang. Hal itu terjadi karena ruangan yang digunakan bukan standar tempat pelatihan. Penyelenggara yang baik adalah harus memperhatikan kenyamanan saat pembelajaran dan kenyamaan ruang belajar. Komponenkomponen yang terkait dengan kondisi dan lokasi tempat pelatihan, antara lain: Efektifitas penyelenggara, Relevansi program diklat dengan pelaksanaan tugas, Persiapan dan ketersediaan sarana diklat, Hubungan peserta dengan penyelenggara diklat, Hubungan antar peserta, Pelayanan Kesekretariatan, Kebersihan \& kenyamanan ruang kelas, Kebersihan \& kenyamanan auditorium, Kebersihan \& kenyamanan ruang makan, Kebersihan \& kenyamanan asrama, Kebersihan Toilet, Kebersihan halaman, Pelayanan Petugas resepsionis, Pelayanan petugas ruang makan, dan sebagainya yang sesuai dengan kebutuhan dari pada diklat itu sendiri.

Komponen lain yang yang perlu untuk di evaluasi dengan cara pertanyaan terbuka, adalah: Yang dirasakan menghambat selama diklat, Pengendali Diklat (MoT) yang ditugaskan, Sarana dan prasarana, Yang dirasakan membantu, Materi yang paling relevan, Materi yang kurang relevan.

Hal ini menjadi masukan bagi penyelenggara agar mempersiapkan ruangan, saana-prasarana dan fasilitas yang memadai sesuai standar kebutuhan pelatihan, sehingga perlu menjadi masukan agar penyelenggara pelatihan memahami kaidah pelatihan dan standar pelatihan yang terakreditasi. Oleh karena itu perlunya bekerjasama dengan Lembaga 
penyelenggara pelatihan yang terakreditasi.

Pembahasan untuk evaluasi Level II, Pengetahuan peserta pelatihan tentang manajemen unit ruang rawat.

Hasil evaluasi menunjukkan bahwa sebelum pelatihan berlangsung Sebagian besar 23 orang (76,7 \%) mempunyai kategori pengetahuan cukup namun evaluasi setelah pelatihan menggambarkan hasil $100 \%$ mempunyai kategori pengetahuan baik dengan nilai evaluasi rata-rata 90. Namun hasil evaluasi pada saat penelitian berlangsung menunjukkan adanya perubahan pengetahuan peserta yaitu $90 \%$ yang mempunyai pengetahuan baik.

Evaluasi adalah penafsiran penilaian terhadap pertumbuhan dan kemajuan komponen/aspek yang dinilai untuk mendapatkan data/informasi pembuktian yang akan menunjukkan sampai dimana tingkat kemampuan dan keberhasilan dalam pencapaian ke arah tujuan yang telah ditetapkan. Hasil penelitian menunjukkan ada peningkatan pengetahuan sebelum pelatihan dan setelah pelatihan. Hal ini sesuai dengan teori Pelatihan dianggap berhasil bila bisa memberi dampak perubahan bagi peserta pelatihan sesuai dengan tuntutan organisasi baik dari sisi pengetahuan maupun keterampilan. [4]

Meningkatnya pengetahuan merupakan sebab akibat dari proses belajar mengajar selama pelatihan dan dipengaruhi oleh tingkat Pendidikan peserta, dimana tingkat Pendidikan yang rata-rata S1/D4. Makin tinggi tingkat pendidikan seseorang, makin mudah menerima informasi sehingga makin banyak pula pengetahuan yang dimiliki. Sebaliknya pendidikan yang kurang akan menghambat perkembangan sikap sesorang terhadap nilainilai yang baru diperkenalkan.

Hal tersebut senada dengan yang diutarakan sikap batin pengetahuan dan tindakan merupakan respon internal setelah adanya pemikiran, tanggapan, yang diperoleh dari proses pembelajaran pendidikan yang didapat seseorang.Hasil penelitian ini sejalan dengan penelitian yang pernah dilakukan tentang
Efektifitas Program Pelatihan Service Excellence di Rumah Sakit Jantung dan Pembuluh Darah Harapan Kita Jakarta. Dimana hasil penelitian menunjukkan bahwa Pelatihan Service Excellence di RS Jantung dan Pembuluh Darah Harapan Kita Jakarta sangat efektif dalam meningkatkan pengetahuan, keterampilan dan sikap kinerja pegawai pasca pelatihan.[2]

Pengetahuan peserta latih mengalami penurunan menjadi $90 \%$ pada saat penelitian, bisa jadi disebabkan oleh adanya faktor masa waktu pelatihan yang sudah berlangsung cukup lama, sehingga memberikan dampak kepada peserta.

Penyelenggaraan pelatihan juga dipengaruhi oleh proses sebelum diseleggarakannya pelatihan, selama penyelenggaraan pelatihan hingga sesudah pelatihan dilaksankan. Efektivitas pelatihan dipengaruhi oleh kualitas trainer dan ketepatan metode pelatihan yang digunakan

\section{KESIMPULAN}

Evaluasi peserta pelatihan terhadap Narasumber yaitu dalam kategori sangat baik dan evaluasi Penyelenggaraan Pelatihan menggambarkan baik. Pengetahuan peserta pelatihan sebelum pelatihan sebesar 76,7\% kategori cukup dan setelah pelatihan $90 \%$ dalam kategori baik.

\section{DAFTAR PUSTAKA}

[1] Huber, D. (2014). Leadership \& nursing care management (5th ed.). St. Louis Missouri: Elsevier Saunders.

[2] Hikmawati, D. (2012). Evaluasi Efektivitas Pelatihan Service Excellence di Rumah Sakit Jantung dan Pembuluh Darah Harapan Kita Jakarta. Skripsi. Universitas Indonesia

[3] Kirkpatrick, D.L. (1998). Evaluating diklatprograms, The four levels, Secondedition. San Francisco: BerrettKoehler Publisher, Inc

[4] Marquis, B. L., \& Huston, C. J. (2015).Leadership roles and management functions in nursing: Theory and 
application (8th ed.). Canada: Lippincot Williams \& Wilkins.

[5] Moekijat. (1990). Evaluasi Pelatihan Dalam Rangka Meningkatkan Produktivitas Perusahaan.Bandung: Penerbit Mandar Maju.

[6] Nurdiana, Haryati, Anisah (2017). Penerapan Fungsi Manajemen Kepala Ruangan Dalam Pengendalian Mutu Keperawatan. JPPNI Vol.02/No.03/Desember2017-Maret 2018. 